\title{
Mercado de trabalho em contexto de pobreza urbana: o caso da cidade de Lichinga, Moçambique.
}

Labor market in the context of urban poverty: the case of the city of Lichinga, Moçambique

Mercado laboral en el contexto de la pobreza urbana: el caso de la ciudad de Lichinga, Moçambique.

Marché du travail dans le contexte de la pauvreté urbaine: le cas de la ville de Lichinga, Moçambique.

\section{Domingos Carlos BATONE}

\section{CpenEdition}

Journals

Edição electrónica

URL: http://journals.openedition.org/espacoeconomia/17258

DOI: 10.4000/espacoeconomia. 17258

ISSN: 2317-7837

Editora

Núcleo de Pesquisa Espaço \& Economia

Refêrencia eletrónica

Domingos Carlos BATONE, « Mercado de trabalho em contexto de pobreza urbana: o caso da cidade de Lichinga, Moçambique. », Espaço e Economia [Online], 19 | 2020, posto online no dia 03 setembro 2020, consultado o 10 setembro 2020. URL : http://journals.openedition.org/espacoeconomia/17258 ; DOI : https://doi.org/10.4000/espacoeconomia. 17258

Este documento foi criado de forma automática no dia 10 setembro 2020.

(C) NUPEE 


\section{Mercado de trabalho em contexto de pobreza urbana: o caso da cidade de Lichinga, Moçambique.}

Labor market in the context of urban poverty: the case of the city of Lichinga, Moçambique

Mercado laboral en el contexto de la pobreza urbana: el caso de la ciudad de Lichinga, Moçambique.

Marché du travail dans le contexte de la pauvreté urbaine: le cas de la ville de Lichinga, Moçambique.

Domingos Carlos BATONE

\section{Introdução}

Apesar de uma década de progresso $54 \%$ da população em 46 países africanos ainda vivem na pobreza, cerca de 544 milhões de pessoas (BAD, OECD E PNUD, 2017). Mais de $80 \%$ dos trabalhadores africanos mantêm empregos informais e a maioria dos funcionários informais são mulheres e jovens (BAD, 2013). No entanto, $85 \%$ das mulheres na África Subsaariana trabalham em empregos mal remunerados ou subvalorizados (ONU Mulheres, 2015). No que concerne ao gênero, empregabilidade e mercado de trabalho em Moçambique, a JICA (2015), considera que mais de $95 \%$ das mulheres estão envolvidas em trabalho não qualificado (agricultura), poucas se envolvem em agricultura comercial, o que gera mais rendimentos e no norte do país, elas permanecem na agricultura de subsistência devido a restrições religiosas e culturais.

2 No que tange a informalidade, o "Doing Business Mocambique 2019" (Banco Mundial, 2019), descreve que grande parte do sector privado em Moçambique permanece informal. Aproximadamente $40 \%$ do PIB do país é atualmente produzido na economia informal e as pessoas que trabalham no sector informal não têm acesso à proteção 
legal, segurança social e previdência. Assim, as empresas informais não têm acesso a financiamento formal e podem ter dificuldade em recrutar mão-de-obra qualificada.

Os Indicadores econômico-financeiros das empresas referentes a 2016 demonstram que o sector empresarial contabilizou 58.023 unidades econômicas, correspondendo a um incremento de $3.8 \%$ em relação ao ano anterior, e empregou 1.402 .070 pessoas ao serviço, o que representou mais de 2.000 postos de trabalho de aumento se comparado com o ano de 2015, conferindo uma variação positiva de 5.2\% e uma dimensão média nacional de 24 pessoas ao serviço (INE, 2018). No final de 2018, estavam registrados nos Centros de Empregos um contingente de 181.403 desempregados no país, dos quais $50,0 \%$ procuravam o primeiro emprego e os restantes um novo emprego (MITESS, 2019). Em 2019 foram registrados 189.846 desempregados, dos quais 50,7\% procuravam o primeiro emprego e os restantes um novo emprego. Por conseguinte, o emprego registrado no $1^{\mathrm{o}}$ trimestre de 2020 , decresceu $41,7 \%$ face ao período anterior (MITESS, 2020b). Através das estatísticas oficiais moçambicanas, observa-se que há uma tendência ao desemprego e o mercado de trabalho continua a mostrar cenários ainda críticos nos últimos anos, principalmente no primeiro trimestre de 2020. Apesar da tendência de abertura das empresas ser positiva, ainda é visivelmente tímida o aumento da oferta de empregos. Assim sendo, esta pesquisa tem como objetivo: (i) verificar o nível de empregabilidade dos candidatos a emprego no contexto de pobreza urbana em Lichinga; (ii) observar a influência das competências exigidas pelos empregadores no funcionamento do mercado de trabalho local; e (iii) analisar a adequação dos cursos profissionais e superiores lecionados no mercado de trabalho local.

4 Em função do contexto apresentado, é levantada a seguinte questão orientadora: em que medida a pobreza urbana influencia o funcionamento do mercado de trabalho em Lichinga?

\section{Uma abordagem conceptual sobre empregabilidade e desemprego}

5 À medida que se implementam inovações técnicas poupadoras de mão-de-obra muitos contingentes de operários são lançados no desemprego, em que se mantêm por certo tempo, até quando a própria acumulação do capital requeira maior quantidade de força de trabalho e dê origem a novos empregos ${ }^{1}$ (Marx, 1996). Assim, duradouro ou temporário, piorando ou não, o desemprego é e sempre foi um flagelo. Não obstante, a grande tragédia é a impossibilidade de prover as necessidades dos desempregados sem agravar as condições do desenvolvimento econômico futuro (Schumpeter, 1961). É por isso que qualquer operário, mesmo o melhor, está constantemente exposto ao perigo do desemprego, que equivale a morrer de fome e são muitos os que sucumbem (Engels, 2010). Esse argumento leva-nos a crer que em muitos contextos o subemprego (emprego precário) equiparasse ao desemprego.

6 O conceito de emprego tomou um significado muito diferenciado se comparado com os anos 1980, onde as pessoas faziam carreira nas organizações e tinham como garantia a estabilidade. Hoje, no entanto, se fala em processos de enxugamento/downsinzing, onde a cada dia existem menos pessoas, realizando mais atividades. Nesse novo mercado, prolifera-se a solicitação de serviços temporários, prestadores de serviços autônomos, trabalhos por dia e por hora, dispensando os profissionais para conciliar diversos tipos de trabalho e interesses profissionais (Malschitzky, 2004). 
7 De acordo com Bolles (2000), sempre haverá empregos disponíveis no mercado, porque mesmo que não houvesse mais nenhuma abertura de novas oportunidades, ou seja, de aumento de quadro de pessoas nas empresas, ainda assim, a possibilidade de ingresso poderia se dar em função das seguintes situações: a) as pessoas que estão empregadas recebem promoções, deixando vagos os postos de trabalho que ocupam, b) as pessoas são demitidas por desempenho insatisfatório no trabalho, deixando mais vagas, outras pedem demissão, ou ainda, c) sofrem lesões sérias no trabalho, nas estradas ou mesmo em casa e tornam-se incapazes de prosseguir trabalhando.

8 Com as mudanças aceleradas no mundo do trabalho, na década de 90, a transformação do perfil do trabalhador exigido pelas empresas, mudou consideravelmente, pois, houve o fim do contrato vitalício entre empregador e empregado, onde havia alguma segurança no emprego em troca de desempenho adequado e fidelidade. Atualmente, o que se espera é que cada trabalhador busque sua empregabilidade (Malschitzky, 2004). A empregabilidade compreende os recursos de um indivíduo, por exemplo, na forma de competência (incluindo conhecimentos, habilidades, atitudes e qualidades pessoais), que também são definidas como capital humano na teoria do capital humano (Becker, 1964). Deste modo, o conceito compreende diferentes tipos de capital social, bem como qualificações formais e a maneira pela qual os recursos de um indivíduo podem ser comercializados para um empregador (Smith, 2010).

9 Um aspecto central de ser empregável é a capacidade de obter um emprego e a capacidade de comercializar-se, negociar e acentuar as competências exigidas por um recrutador. Um candidato a emprego está basicamente se vendendo a empregadores (Knight e Yorke, 2004). Em termos materiais, empregabilidade é operacionalizada em processos de recrutamento e seleção, nos quais graduados e possíveis empregadores se envolvem num ambiente racional onde a competência individual, o capital pessoal e o capital social e cultural são avaliados com as qualificações necessárias para ocupar uma posição (Nilsson, 2017). Assim, o conceito de empregabilidade compreende mais do que a experiência e capacidade de um indivíduo para corresponder as demandas do mercado de trabalho. Por essa razão, a empregabilidade depende do contexto onde é empregado e envolve a relação entre formação educacional, estruturas ocupacionais, demanda e oferta de trabalhadores qualificados no mercado de trabalho. Nestes moldes, as qualificações formais e graus adquiridos através do ensino superior ou profissional oferecido num determinado local, tem importância considerável na empregabilidade de um indivíduo.

10 A empregabilidade significa deste modo, a capacidade de preparar-se para conquistar um novo emprego, a habilidade de mantê-lo ou mesmo a possibilidade de mudar para outro com melhores condições, sem negligenciar a forma como o candidato usa as suas competências, autoconhecimentos, bagagem e experiência pessoais para mover-se de forma auto-suficiente no mercado de trabalho.

\section{Abordagens teóricas sobre mercado de trabalho}

11 Em termos conceptuais, o mercado de trabalho não é, somente, referente ao espaço de relações econômicas, de procura e oferta, onde uns (organizações) procuram profissionais ou força de trabalho, e outros (potenciais candidatos ao emprego) procuram oportunidades para trabalhar e ganhar o salário para sustentar a sua vida, envolve também, entre outras coisas, por exemplo, a rejeição de um formado 
(graduado) que concluiu o curso com êxito, por não reunir requisitos para ingressar a uma vaga (Ucama, 2014).

De acordo com Almeida (2014), o primeiro modelo teórico é o meritocrático, cuja tese defende que a posição dos indivíduos na sociedade é consequência do mérito, posição conquistada com base no merecimento, empenho e esforço que cada um comprove ser capaz de mobilizar ao longo da sua vida; o segundo modelo teórico é o credencialista, onde para a atribuição das funções a desempenhar, a tônica é colocada nas credenciais escolares, em detrimento dos conteúdos, dos saberes e das competências demonstradas (isto porque para os empregadores os diplomas funcionam como que um sinal que lhes permite estimar as prováveis capacidades produtivas dos indivíduos).

13 A terceira proposta teórica é a marxista. Sustenta-se na ideia de que o capitalismo é um sistema em que os meios de produção são detidos e controlados por uma pequena minoria privilegiada. Subsequentemente, os indivíduos que não detêm o controle dos recursos produtivos são forçados a alienar a sua força de trabalho. Nesse sentido, a qualificação (acadêmica e profissional) desempenha a função de perpetuar a ordem econômica e social estabelecida pela classe dominante (Almeida, 2014). Assim, esta teoria defende que as escolas de todos os níveis "legitimam as divisões de classe" e produzem a força de trabalho indispensável para a preservação do sistema capitalista. Para Marx (1996), dentro do sistema do salariado, o valor da força de trabalho se fixa como o de outra mercadoria qualquer; e, como distintas espécies de força de trabalho possuem distintos valores ou exigem para a sua produção distintas quantidades de trabalho, necessariamente têm que ter preços distintos no mercado de trabalho.

14 A quarta proposta, da Teoria do Capital Humano, o Mercado de Trabalho valoriza as competências (Conhecimentos, Habilidades e Atitudes) como se fosse uma mercadoria, não deixando de ter uma proximidade da abordagem marxista.

Nos anos 1950 e 1960 os trabalhos de Jacob Mincer, Theodore Schultz e Gary Becker estabeleceram as bases para a compreensão da relação entre educação, produtividade e renda do trabalhador. Esses trabalhos deram origem ao que se conhece como "teoria do capital humano", segundo a qual a educação dota as pessoas de conhecimentos e habilidades capazes de torná-las mais produtivas e, assim, ganhar mais renda (Kelniar et al, 2013). Os dois economistas neoclássicos que formularam essa teoria (Schultz, 1961, 1980; Becker, 1962, 1993) obtiveram o Prêmio Nobel de Economia, e o mereceram porque reconheceram a existência de um novo facto histórico: que o conhecimento tinha-se tornado semelhante ao capital físico, e que o investimento em educação é o modo pelo qual os indivíduos "acumulam" esse patrimônio e dele derivam ganhos ou rendimentos (Bresser-Pereira, 2011). O principal pressuposto da Teoria do Capital Humano, é o de que os investimentos feitos pelo indivíduo em sua educação formal, na sua formação e treinamento profissional e na aquisição de outros conhecimentos serão determinados pela relação entre os benefícios futuros que espera receber por estes investimentos no mercado de trabalho e os custos associados aos mesmos (Santos, 2010).

16 A acumulação de capital humano pode beneficiar uma sociedade como factor de produção de bens finais da economia e contribui para o progresso tecnológico, através da geração e/ou a adoção de novas tecnologias, permitindo a elevação da produtividade da economia e o crescimento econômico de longo prazo (Barbosa et al, 2011). Para a Teoria do Capital Humano, a educação tem influência determinante na renda do 
trabalhador. Ela melhora as habilidades e consequentemente a produtividade, o resultado podem ser observado no aumento de sua renda (Kelniar et al, 2013).

Segundo Drucker (2001), atualmente os empregos exigem mais conhecimento dos trabalhadores, e que os mesmos para se manterem empregados devem estar em um processo de aprendizado contínuo. Assim sendo, a ascensão de classe e melhoria na renda são para este autor um desafio. Por exemplo, na percepção do Banco Mundial (2010), a discrepância entre as qualificações e a procura, salários iniciais abaixo das expectativas dos graduados, poucas oportunidades de trabalho e condições políticas instáveis são também responsáveis pela emigração de graduados dos países africanos e pela relutância dos que estudam no estrangeiro em regressar aos seus países de origem. Portanto, a drenagem de cérebros subtrai continuamente alguns dos mais qualificados de todo o capital humano interno acumulado. Para essa organização, a emigração líquida da África Subsaariana foi de $570 \mathrm{mil}$ pessoas em 1995, decaiu para $290 \mathrm{mil} \mathrm{em}$ 2000 , tendo depois subido para 1,07 milhões em 2005. Estima-se que um terço delas tivesse formação universitária. Entendemos, que Moçambique não fica alheio a situação e contribui também para engrossar esses números.

18 Assim sendo, a presença de instituições de ensino superior e institutos de formação profissional, favorece no desenvolvimento do capital humano, provendo a população local de capacidades e/ou competências (conhecimentos, habilidades e atitudes) para promover comportamentos ou soluções pro-desenvolvimento, no entanto, deve haver capacidade interna do mercado para absorver todo o capital humano criado, evitando deste modo, a evasão de quadros superiores (Batone, 2020).

\section{As dimensões do conceito de pobreza e pobreza ubana}

19 A investigação em torno da pobreza urbana tem uma tradição muito maior nos países ocidentais do Norte, onde a maioria da população vive predominantemente em áreas urbanas desde a primeira metade do século XX. A pobreza urbana em África é um tópico de pesquisa relativamente recente (Barbelo, 2007). Para contextualizar e desconstruir os conceitos de pobreza e pobreza urbana, Vasconcelos (2006), adianta explicando a relatividade destes conceitos, alegando que ele varia no tempo e no espaço. Quem era considerado pobre no século XVI não seria o mesmo no século actual.

De acordo com Rodrigues et al (2000), no meio urbano a pobreza reveste formas mais visíveis e extremas de exclusão. A pobreza urbana afeta diversos grupos sociais, refletindo problemas associados a baixos rendimentos e desemprego, à falta de qualificações (e a incapacidade de as desenvolver), à precariedade do emprego, às situações de doença ou de problemáticas sociais diversas (toxicodependência, alcoolismo, deficiência etc.), às pressões subjacentes aos processos de urbanização, estando estas associadas a mecanismos de descriminação e de segregação espacial, consumo e tráfico de drogas, a prostituição, a delinquência e formas de desordenamento territorial.

21 A persistência da pobreza e de necessidades essenciais não satisfeitas; o aumento das desigualdades e a permanência das práticas de violação de liberdades políticas elementares e de liberdades formais básicas; a precarização do trabalho e a crescente vulnerabilidade do trabalhador; a tendência cada vez maior de exclusividade de espaços residenciais e comerciais, privatização de espaços públicos e estigmatização de espaços populares, estão também associadas a questão da pobreza urbana (Souza, 2018). Nestes 
moldes, o prêmio Nobel de Economia de 2001, Stiglitz (2003), considera que há uma tendência do aumento da desigualdade nos países pobres, pois, uma parcela desproporcional dos lucros foi para os mais ricos, os $30 \%$ superiores, ou até para os $10 \%$ superiores, enquanto muitos dos pobres, na verdade, empobreceram ainda mais.

De acordo com outro prêmio Nobel de Economia de 1998, Sen (2000), a pobreza existe quando as pessoas não possuem as capacidades necessárias para alcançarem um nível adequado de rendimento, de boa saúde e educação, de segurança, de autoconfiança e de liberdade de expressão, entre outros. Deste modo, a pobreza está associada à privação de liberdades reais de que uma pessoa goza, tais como: liberdades políticas, disponibilidades econômicas, oportunidades sociais, garantias de transparência e proteção da segurança. Essa privação tem como fontes: a tirania, carência de oportunidades econômicas e destituição social sistemática, negligência dos serviços públicos e intolerância ou interferência excessiva de Estados repressivos.

Ao descrever as características da pobreza urbana através das condições sanitárias dos operários ingleses da cidade, Engels (2010), descreve que nesses bairros, a sociedade chegou a um nível de pobreza e de degradação realmente indescritível. As habitações dos pobres são em geral muito sujas e aparentemente nunca são limpas; a maior parte das casas compõe-se de um só cômodo que, embora mal ventilado, está quase sempre muito frio, por causa da janela ou da porta quebrada.

Isso significa que a pobreza urbana está presente em todos contextos. Para o caso de África, os argumentos apresentados por Collier (2007), demonstram que os países mais pobres do mundo continuam a experimentar a miséria devido a quatro armadilhas que tem recebido menos atenção pelos seus governos. A primeira armadilha é a do conflito armado, hoje $73 \%$ da população do continente africano está envolvida em algum tipo de conflito armado ou esteve recentemente em guerra civil, a derradeira para o status de pobreza que estas populações enfrentam, uma vez que tanto a guerra torna mais pobres estes países como a pobreza que eles enfrentam causa a guerra. Outra parcela da população africana está presa numa armadilha diferente, a dos recursos naturais: $29 \%$ das pessoas residem em países onde a política é diretamente influenciada por altas receitas provenientes de recursos naturais, como petróleo e diamantes, visto que, a exportação de recursos naturais aumentam o valor relativo da moeda do país dificultando a exportação de outros produtos e, por vezes, devastando sectores como alguns serviços e a agricultura. Da mesma forma, $30 \%$ dos africanos que vivem em condições de interioridade continental e escassez de recursos naturais fazem vizinhança com países que dificultam o seu crescimento como nações e $76 \%$ das pessoas deste continente padecem da má governação e de péssimas políticas públicas.

Para o professor Collier, uma má governação acaba com a maioria das chances de crescimento destes países. Exemplos como a corrupção, sucessivos golpes de Estado ou mesmo a falta de preparação técnica de alguns governos contribuem significativamente para manter cerca de mil milhões de pessoas à margem do crescimento socioeconômico (na pobreza, penúria e sofrimento). Contudo, a saída da pobreza para alcançar o desenvolvimento numa determinada região requer algumas mudanças, assim, para Schumpeter (1997), esse processo envolve a inovação que ocorre através da criação de novas combinações na economia com a introdução de um novo bem, introdução de um novo método de produção, abertura de um novo mercado, conquista de uma nova fonte de oferta de matérias-primas ou de bens semimanufaturado e o estabelecimento de uma nova organização de qualquer indústria. 


\section{Metodologia} procedimentos quantitativos e qualitativos. No âmbito dos dados quantitativos, recorreu-se a informação estatística disponível, nomeadamente, o Censo da População e Habitação de 2017, as quatro avaliações da pobreza em Moçambique baseados nos dados do Inquérito aos Agregados Familiares (IAF) (referentes aos anos 1996/97 e 2002/03) e o Inquérito aos Agregados Familiares sobre Orçamento Familiar (IOF) (relacionados aos anos 2008/09 e 2014/15). Através do inquérito desenvolvido entre as organizações empregadoras da Cidade de Lichinga, bem como os candidatos a emprego, foram analisadas as competências necessárias exigidas para acederem ao mercado de trabalho e a sua empregabilidade. Participaram 340 candidatos a emprego e 37 respondentes que desempenham as funções de Direção nas organizações empregadoras. Entre os empregadores que responderam ao questionário, $47 \%$ são Directores Gerais/ Presidentes do Conselho de Administração, 43\% são chefes da Repartição de Recursos Humanos e $10 \%$ são diretores de operação.

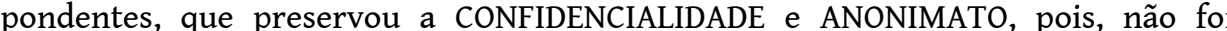
solicitado o nome do candidato a emprego ou dos representantes das organizações empregadoras que aceitaram participar deste estudo. Assim sendo, o facto da pesquisa ter sido desenvolvida em épocas de COVID-19, em que o distanciamento social foi uma das medidas de prevenção, os inquéritos organizados foram digitais por via dos links associados ao googleforms (Google questionários).

\section{Resultados}

\section{A pobreza urbana na cidade de Lichinga}

Em Moçambique, as cidades têm um desempenho melhor que as áreas rurais em termos de redução da pobreza. De facto, os níveis de pobreza declinaram mais depressa nas áreas urbanas que nas rurais. Entre 1996/7 e 2008/9, a pobreza declinou em 24 pontos percentuais nas áreas urbanas, comparativamente a 10 pontos percentuais nas áreas rurais. Como acontece na maior parte dos países, a urbanização e o crescimento económico parecem acontecer a par e passo. Contudo, a pobreza urbana continua elevada, a 49 por cento (BANCO MUNDIAL, 2017).

31 ferir com o método histórico. A cidade de Lichinga é a capital da província do Niassa 
(Figura 1), localizada a $2.800 \mathrm{~km}$ de Maputo, capital de Moçambique. Os dados referentes a pobreza desta cidade vão ser analisados através das avaliações feitas sobre a incidência deste fenômeno na província, através duma comparação entre o meio urbano versus meio rural, para em seguida verificarmos a situação da pobreza na cidade.

Figura 1: Mapa de Moçambique e localização da Cidade de Lichinga

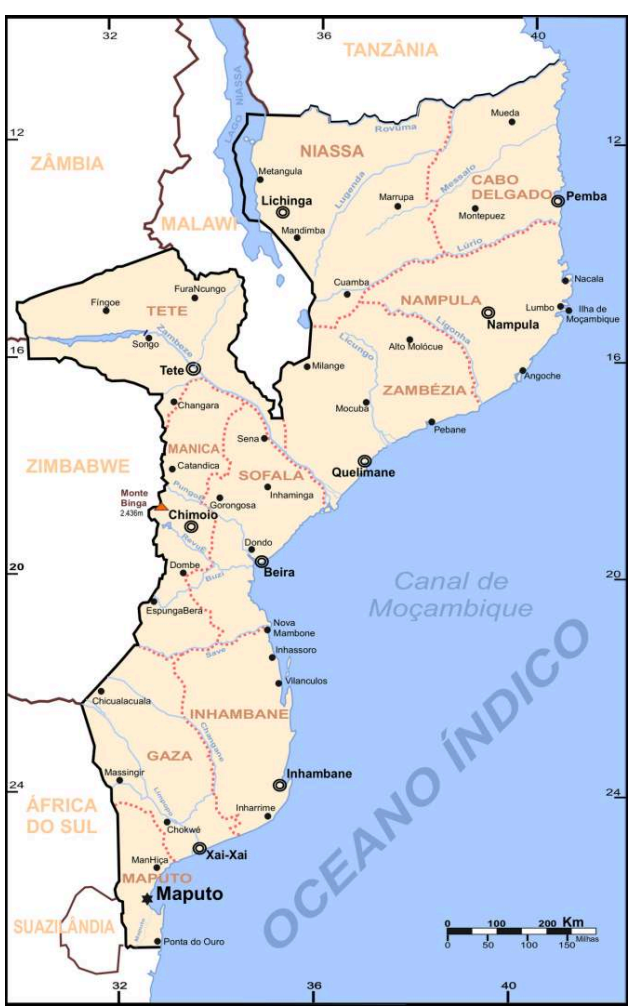

Fonte: https://pt.wikipedia.org/wiki/Geografia_de_Mo\%C3\%A7ambique.

A Norte localizam-se os distritos de Mandimba e Metarica, a Sul estao os distritos de Mecanhelas e Gurue, a Este os distritos Lalaua, Malema, Gurue. Finalmente, Mecanhelas na zona sul.

De acordo com os dados do Instituto Nacional de Estatística (2017), referentes ao IV recenseamento da população e habitação, a cidade de Lichinga tem cerca de 213.361 habitantes, numa superfície de 2.054,94 Km2, correspondendo a 104 habitantes $/ \mathrm{km} 2$. No âmbito da educação, os dados indicavam que entre 2014/15 a taxa de analfabetismo era 58\%. Na saúde a relação médico/população é de 6.0/100.000 habitantes. Cerca de $39,1 \%$ de pessoas tem acesso a água potável, mas também, apenas $12 \%$ tem acesso a energia elétrica.

Fica claro que maior parte dos jovens e a população da província de Niassa é desprovida de rendimentos para aumentar as capacidades de escolha dos serviços essenciais de saúde, educação, abastecimento de água e segurança, ou seja, observa-se a falta de oportunidades econômicas, a negligência de serviços públicos e uma repreensão policial muito forte que viola os direitos humanos. Por exemplo, a morte de 2 pessoas e 5 feridos, por excesso do uso da força e balas verdadeiras por parte da polícia, a morte de uma mulher grávida que foi batida com chambocos, no quadro do cumprimento do 
decreto presidencial de Estado de emergência no país, conforme foi reportado pelo jornal "Watenguele do dia 05 de Junho de 2020".

A Cidade de Lichinga e a província do Niassa têm o problema crônico do desemprego, um fenômeno que deve ser levado pelo governo local. Observando para a evolução deste fenômeno através do registo do desemprego do fim de cada ano, o Ministério do Trabalho e Segurança Social-MITESS (2019), observou os seguintes números na província: 5.087 desempregados (em 2014), 5.200 desempregados (em 2015), 5.448 desempregados (em 2016), 5.640 desempregados (em 2017), 570 desempregados (em 2018). $O$ ano de 2019 o mercado de trabalho local experimentou uma situação diferente, pois, registaram-se um total de 515 desempregados (MITESS, 2020a), destacando assim, uma redução substancial de quadros disponíveis no mercado sem exercer nenhuma atividade produtiva formalmente remunerável. No fim do primeiro trimestre de 2020, aquando da adoção das primeiras medidas de prevenção do COVID-19 em Moçambique, observou-se que no Niassa a procura de emprego aumentou 21,9\%, e o desemprego cresceu para 624 pessoas (MITESS, 2020). Esses dados apenas são do desemprego declarado pelos candidatos formalmente, o que significa que o número pode ser bem alto, levando em consideração os que atuam no sector informal e não declaram a sua situação de desempregado nos Institutos e Centros de Emprego moçambicanos. Nestes moldes, a situação agudiza-se devido a redução das oportunidades no mercado de trabalho causado pelo encerramento de muitas empresas, o que significa que até ao fim do ano os números irão disparar.

Os únicos resultados positivos são apresentados pelo Plano Estratégico do Niassa (2018-2029), que baseia-se apenas no crescimento econômico (capacidade de produção de dinheiro e riqueza) e não no impacto real deste crescimento na vida da população (desenvolvimento econômico), apesar de assumir que a província tem o menor crescimento da região e do país, o governo provincial celebra descrevendo que a província nos últimos 10 anos tem demonstrado um crescimento positivo, tendo em conta que a taxa de crescimento médio da produção global rondou os $14,01 \%$ e com uma contribuição média no PIB nacional em 3\% (menor taxa da região Norte). Em 2010 o PIB da província foi cerca de 10.293,9 Milhões de Meticais, mostrando um crescimento de 71,3\% em relação a 2015 que foi de 17.631,6 Milhões de Meticais (Governo do Niassa, 2017).

Para o caso particular da província do Niassa, os dados evidenciam uma evolução substancial na redução da pobreza dos 70,6\% (entre 1996-97) para 52,1\% (entre 2002-03), e 31,9\% (entre 2008-09). No entanto, nos anos seguintes o nível de incidência da pobreza duplicou de forma assustadora, se comparado com o período anterior, passando para 65,3\% (entre 2014-15) (MEF/DEEF, 2016). Em cerca de 19 anos ainda há traços visíveis de pobreza, conforme os resultados oficiais ilustraram, o que demonstra um contexto de precariedade da população local. Concordamos com a posição de que as grandes variações observadas nas taxas de pobreza podem depender de vários factores, tais como: as mudanças na produção agrícola, nos preços dos bens alimentares, na existência de oportunidades de rendimento fora da agricultura, os quais não são estáveis ao longo do tempo e podem ter uma influência grande nas taxas de pobreza (MEF/DEEF, 2016). Por exemplo, as vidências trazidas por Maloa (2016), mostram que as condições de vida da população periférica da Cidade de Lichinga (por exemplo, nos bairros de Lulimile, Nomba e Chiuaula) caracterizam um verdadeiro acampamento urbano, ou seja, um verdadeiro "inferno urbano", onde dia após dia crescem as 
periferias sem infra-estruturas físicas e sociais, onde se acumulam pessoas em condições desumanas ou indigentes (Figura 2).

Figura 2. Bairro periférico da Cidade de Lichinga (Nomba)

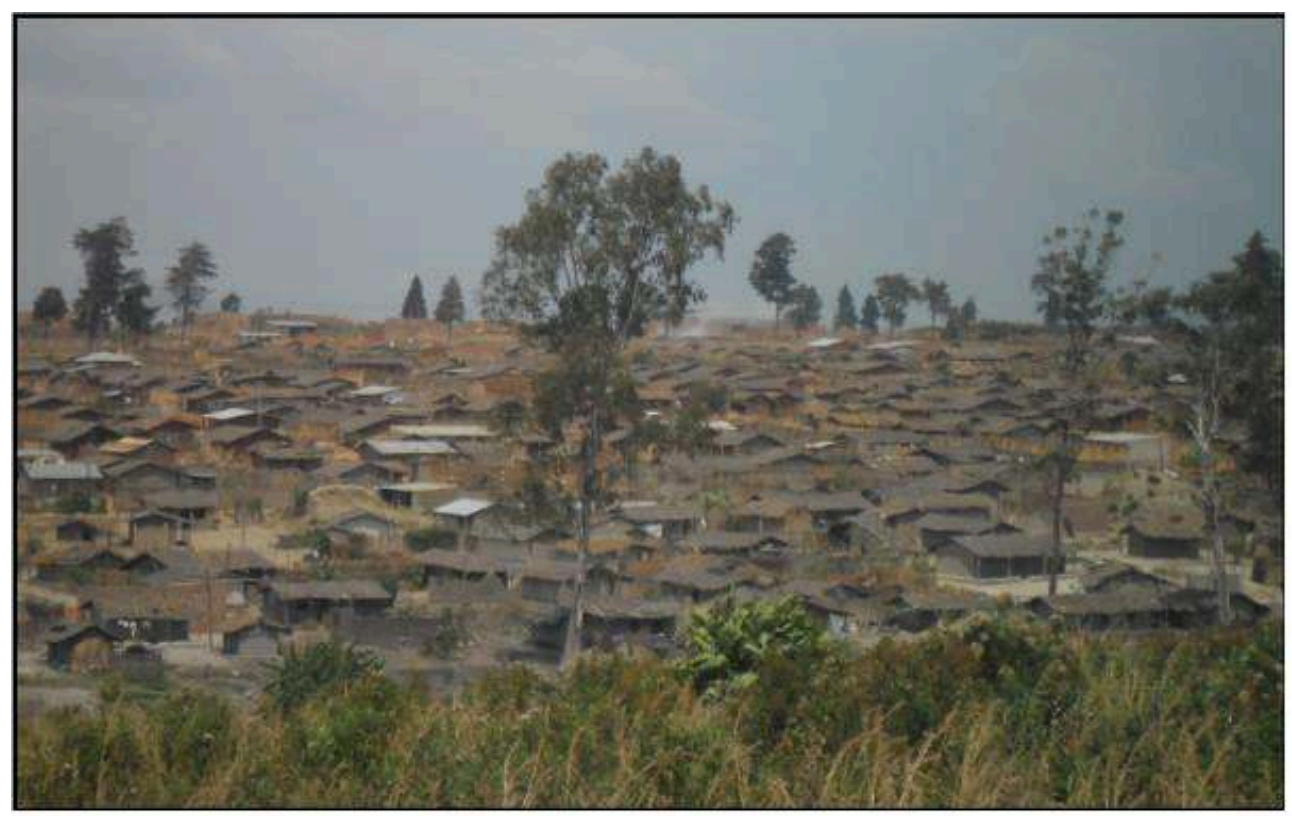

Fonte: Maloa (2016)

Outros bairros, como Nzinje, Muchenga e as zonas de expansão têm características mistas, observando-se um desenvolvimento um pouco parcelado através da construção de habitações de alvenaria com chapas de zinco, no entanto, com poucas casas cobertas de capim e quintais também feitos pelo mesmo material.

A pobreza na cidade de Lichinga também pode ser resultado da exclusão dos jovens no mercado de trabalho. Segundo Rodrigues et al (2000), a pobreza e a exclusão reforçamse mutuamente, visto que, a exclusão do mercado de trabalho gera pobreza e esta impede o acesso a bens e serviços socialmente relevantes (habitação, saúde, lazer). Um excluído será aquele que não consegue configurar uma identidade (social) no trabalho, na família ou na comunidade. Torna-se um excluído das relações sociais e do mundo das representações a elas associadas.

40 A vulnerabilidade material e social nas áreas urbanas de Lichinga também estão associadas a precariedade dos serviços básicos de saúde, abastecimento de água e falta de oportunidades para geração de fontes de renda alternativas diferentes da agricultura familiar de subsistência praticada nos bairros periféricos (Chiulugo, Ntoto, e outros). No entanto, o aumento das Instituições de Ensino Profissional (IEP) e Instituições de Ensino Superior (IES) na Cidade de Lichinga e Província de Niassa, cria mais esperança para as famílias, visto que, elas acreditam que podem aceder ao trabalho assalariado formal por meio da aquisição de uma qualificação. Contudo, os resultados da educação só poderão continuar a ter impactos positivos se as oportunidades aumentarem através da abertura de mais empresas, mais investimentos para projectos globais, industriais e a promoção do auto-emprego, o que está acontecendo de forma diminuta. Em termos de administração territorial e gestão de espaços urbanos, o processo de expansão da Cidade de Lichinga devia ser planificada e acompanhada pelas infra-estruturas básicas de saúde, educação, segurança, água, 
bancos e mercados, evitando dessa forma a ruralização da cidade, assim sendo, urge o desenho dum "Plano de Urbanização".

41 Conforme assegurou Barbedo (2007), o aumento da dimensão territorial das Metrópoles africanas é acompanhado de dois fenômeno concomitantes de ocupação do território, um de dispersão (sprawl) e outro de compressão (packing), através dos quais se reproduzem bolsas de pobreza. Estes fenômeno, pela sua dimensão territorial, afetam a capacidade da cidade funcionar como uma entidade única, resultando na fragmentação territorial e no aparecimento da "cidade informal" surgindo novos ambientes urbanos com a tendência de gerar anéis periféricos de pobreza em torno da cidade formal. Nessa lógica, os bairros de expansão na cidade de Lichinga tendem a ser composto por habitações mais dispersas (sprawl), sem acompanhar a presença de infra-estruturas básicas estruturadas, por exemplo, os mercados nas zonas de expansão são desorganizados, com bancas precárias e problemas sérios de saneamento, onde existem depósitos de lixo sem contentores.

Quanto ao ambiente de negócios local, o "Doing Business Moçambique 2019”, considera que na cidade de Lichinga ainda é difícil abrir uma empresa, pois, numa classificação de 0 a 10, foi atribuída a posição 5 , mas também, uma pontuação de 61,33 na escala de 1 a 100; em relação ao registo de propriedades, usando os mesmos parâmetros, a classificação é de 4 e a pontuação de 54,18 ; finalmente, a execução de contratos é que tem melhores resultados, sendo a terceira melhor do país, com a classificação de 3 e uma pontuação de 57,37. No entanto, há muitos procedimentos para o licenciamento de empresas (cerca de 11), e o tempo de espera para sair a licença é maior (aproximadamente 34 dias). E o caso do registo de propriedade, os processos também são numerosos (7) e o empreendedor ou interessado levaria cerca de 42 dias a espera do despacho final (Banco Mundial, 2019).

Naturalmente, apesar dos números mostrarem alguma redução significativa da pobreza nos primeiros anos (1996/97 a 2008/09), os anos subsequentes (2014/2015 a 2020) a pobreza teve tendências crescentes devido ao mau ambiente de negócios na Cidade de Lichinga e Niassa, a falta duma estratégia clara de desenvolvimento industrial, bem como a ausência duma política de emprego ativa no Niassa, retirando a possibilidade dos recém-graduados apostarem no empreendedorismo e no auto-emprego, quando as vagas criadas localmente, não são suficientes para absorver a mão-de-obra qualificada disponível. Esses fatores, vistos de forma conjugada, podem servir de catalisadores para perpetuar o ciclo da pobreza nas famílias.

\section{A empregabilidade e mercado de trabalho na cidade de Lichinga: a perspectiva dos candidatos a emprego}

44 Algumas estatísticas produzidas sobre Moçambique, considerando os trabalhadores familiares não remunerados como subempregados, evidenciam que as taxas de subemprego dispararam para quase 40 por cento, em 2009. Mais, o progresso tem sido geograficamente desigual, com os mais pobres concentrados nas áreas rurais e nas regiões Centro e Norte (Banco Mundial, 2017).

No âmbito dos empregos criados, a Intervenção de Sua Excelência Filipe Jacinto Nyusi, Presidente da República de Moçambique, por Ocasião da Inauguração da Direção Provincial do Trabalho, Emprego e Segurança Social de Niassa, em 2016, evidencia claramente o peso do sector informal e dos trabalhadores por conta própria, quando 
falamos de mercado de trabalho local, pois considera que em 2015 e 2016 foram inscritos em todo o País, 20.102 novas empresas, tendo a província de Niassa registrados 544. Registaram-se 189.550 trabalhadores por conta de outrem, sendo 5.722 desta província. Por conta própria, registamos em todo o País, 10.417 trabalhadores, dos quais 583 são de Niassa, possibilitando que os mesmos possam beneficiar dos seus direitos legalmente previstos. (Intervenção de Sua excelência Filipe Jacinto Nyusi, 2016, p. 3). ${ }^{2}$

No que concerne a força de trabalho local, os dados oficiais são optimistas, destacando que a taxa de emprego ao nível da província situa-se em $62,4 \%$, sendo $67,9 \%$ nos homens e $57,4 \%$ nas mulheres e registou uma taxa de desemprego de $26,2 \%$ sendo as mulheres com uma percentagem de $31,0 \%$ e homens com $21,1 \%$ (Governo do Niassa, 2017; INE, 2017).

De acordo com o MITESS (2019), o desemprego registrados no fim de cada ano no Niassa foi de: 5.087 desempregados (em 2014), 5.200 desempregados (em 2015), 5.448 desempregados (em 2016), 5.640 desempregados (em 2017), 570 desempregados (em 2018). Esses dados apenas são do desemprego declarado pelos candidatos formalmente, o que significa que o número pode ser alto, levando em consideração os que atuam no sector informal e não declaram a sua situação de desempregado nos Institutos e Centros de Emprego moçambicanos.

O ano de 2019 experimentou uma situação diferente no mercado de trabalho local, pois, registaram-se um total de 515 desempregados (MITESS, 2020a), destacando assim, uma redução substancial de quadros disponíveis no mercado sem exercer nenhuma atividade produtiva formalmente remunerável.

No fim do primeiro trimestre de 2020, observou-se que no Niassa a procura de emprego aumentou $21,9 \%$, e o desemprego cresceu para 624 pessoas (MITESS, 2020). Esse facto agudiza-se devido a redução das oportunidades no mercado de trabalho causado pelo encerramento de muitas empresas, o que significa que até ao fim do ano os números irão disparar. As evidências da Confederação das Atividades Econômicas de Moçambique (CTA) (2020), revelam que por conta dos impactos do COVID-19, muitas empresas dos sectores de Turismo, Transportes (Aviação Civil e transporte rodoviário) e Agricultura, enfrentam grandes dificuldades para continuar com as suas atividades, ponderando a possibilidade de encerrar as suas atividades (algumas inclusive já o fizeram).

50 A experiência prática no terreno demonstra que a situação da empregabilidade ainda é caracterizada por um grande desnível entre a oferta de recursos humanos qualificados formados pelas Instituições de Ensino Superior (IES) ou Instituições de Ensino Profissional (IEP) e as vagas criadas pelas organizações a atuarem na Cidade de Lichinga, principalmente neste período de crise global. Através da entrevista obtida com o Delegado Provincial do IFPELAC, Paulo Matapa, foi possível constatar que existem poucos empregadores na cidade para responder a tanta oferta de recursos humanos qualificados na cidade, possibilitando situações de subemprego, desemprego e fuga de quadros para outras cidades com elevado mercado de trabalho.

51 Esse facto é consubstanciado por Almeida (2014), ao assegurar que a sobrequalificação acadêmica (excesso de qualificações) pode gerar à desvalorização dos diplomas, onde os trabalhadores investem em mais educação para garantirem o seu emprego, o que se poderá consubstanciar num excesso de qualificações, tornando-se paradoxalmente num 
autêntico obstáculo à inserção laboral, principalmente em mercados de trabalho sem capacidade de absorção dos seus diplomados.

Através do exemplo da Faculdade de Gestão de Recursos Florestais e Faunísticos (FAGREFF), da Universidade Católica de Moçambique, foi possível verificar que maior parte dos quadros formados por esta Instituição de Ensino Superior tem sido absorvido pelo mercado logo depois da formação, ou seja, tem maior empregabilidade, tal como descreveu o Diretor da Faculdade, Felipe André Angst, PhD.

No caso dos quadros formados pela UniRovuma (ex-Universidade Pedagógica), o Professor Agostinho Molesse considera que, muitos são absorvidos pelo mercado de trabalho local com destaque para o sector de educação (que era a especialidade da UP) e atualmente assiste a outros sectores de atividades fornecendo mais candidatos diferenciados ao mercado, nomeadamente, o agrário, defesa e segurança. No entanto, maior parte dos formados por esta instituição de ensino superior já tem um emprego, apenas inscrevem-se para adquirir novas competências e progredir através da aquisição de novas qualificações.

54 Seguindo estes raciocínios, o empreendedorismo e o auto-emprego podem ser uma alternativa viável em Lichinga, tal como referenciaram Paulo Matapa e Felipe André Angst, por essa razão, deve ser criado um bom ambiente de negócios local, visto que há muitas barreiras para abrir/licenciar uma empresa e ter o registo de propriedade nesta cidade. Pois vejamos, de acordo com o "Doing Business Moçambique 2019" (Banco Mundial, 2019), na cidade de Lichinga ainda é difícil abrir uma empresa, visto que, numa classificação de 0 a 10, foi atribuída a posição 5 , mas também, uma pontuação de 61,33 na escala de 1 a 1003; em relação ao registo de propriedades, usando os mesmos parâmetros, a classificação é de 4 e a pontuação de 54,18; finalmente, a execução de contratos é que tem melhores resultados, sendo a terceira melhor do país, com a classificação de 3 e uma pontuação de 57,37. No entanto, há muitos procedimentos para o licenciamento de empresas (cerca de 11), e o tempo de espera para sair a licença é maior (aproximadamente 34 dias). E o caso do registo de propriedade, os processos também são numerosos (7) e o empreendedor ou interessado levaria cerca de 42 dias a espera do despacho final.

Através da pesquisa desenvolvida por Ali (2017), cujos casos de estudo foram as empresas Florestas de Niassa e a Niassa Green Resources, onde problematizava a expectativa governamental de criação de mais empregos para a população do Niassa, observou um cenário diferente no terreno, pois, as características deste mercado de trabalho eram de subemprego, nomeadamente, o emprego é majoritariamente casual, mal remunerado e desenvolvido em condições sociais de trabalho precárias, reparando para a estrutura de emprego, para o sistema de recrutamento e de pagamento e para as condições de trabalho que incluem a organização social do trabalho, da alimentação, do alojamento, do transporte, as condições de segurança laboral e social, entre outros aspectos da organização social em que o trabalho se desenvolve, mais amplamente.

Nesse sentido, mesmo que os candidatos a emprego, sejam empregáveis e uma parte esteja a ser absorvido pelo mercado de trabalho, o subemprego acaba marginalizando os trabalhadores, ou seja, existe uma fronteira fina entre o desemprego e um emprego com péssimas condições, razão pela qual em alguns contextos são tratados como sinônimos. Deste modo, é importante que a estrutura do emprego tenha boas condições de trabalho. 

que querem mudar de trabalho por uma oportunidade melhor, evidenciou que o mercado de trabalho não funciona plenamente e há menor empregabilidade, dado que, são lançados concursos de ingresso para formalização de candidatos que a prior já foram selecionados com base em critérios baseados no nepotismo, empreguismo e amiguismo, em detrimento do mérito e qualificação. Dos candidatos a emprego inquiridos na Cidade de Lichinga, um número maior deles (65\%) consideram que já foram vítimas da corrupção, para poderem ser incorporados no mercado de trabalho local, no entanto, $35 \%$ nunca foi lhe pedido uma propina ou pagamento por parte das organizações empregadoras e seus intermediários.

cidade de Lichinga pode melhorar, se forem operacionalizadas as seguintes medidas: (i) apostar na instalação de grandes investimentos e promover grandes negócios; (ii) melhorar o perfil acadêmico; (iii) melhorar as capacidades humanas dos candidatos, durante a formação; (iv) melhorar o processo de recepção e filtragem dos documentos dos candidatos; (v) garantir a transparência no processo de seleção de quadros; (vi) criar mais oportunidades de emprego para jovens; e (vii) reduzir os atuais níveis de favoritismo e de corrupção.

\section{As competências exigidas no mercado de trabalho de Lichinga: uma perspectiva dos empregadores}

61 Das organizações inquiridas, 27\% foram organizações públicas do aparelho do Estado, $44 \%$ são ONG's e organizações da sociedade civil e $29 \%$ fazem parte das empresas privadas.

62 Nesse sentido, algumas explicações sobre a tendência das competências exigidas pelos empregadores baseiam-se no credencialismo (valorização dos diplomas) ou no mérito dos candidatos. Através dos resultados obtidos no terreno foi possível observar que muitas organizações a operarem na cidade de Lichinga tem como prioridade a qualificação acadêmica e profissional, revelando uma tendência para o credencialismo. 
63

so estudo verificou que os empregadores (sector público/aparelho do Estado, sector privado e ONG's), exigem com muita frequência várias competências. Assim sendo, os atributos determinantes para as organizações contratarem um candidato em Lichinga, num contexto de extrema pobreza urbana são:

1. Experiência pessoal e profissional, que é extremamente determinante (58\%), muito determinante (28\%), moderadamente determinante (14\%);

2. Mérito (Habilidades/saber fazer), com cerca de $71 \%$ de empregadores a considerar extremamente determinante, $29 \%$ era muito determinante;

3. Qualificação acadêmica (Nível de Escolaridade), constitui o principal atributo apontado pelos empregadores para selecionarem os candidatos, visto que, $85 \%$ assumiram ser extremamente determinante e $15 \%$ muito determinante;

4. Domínio da informática e TIC's, obteve cerca de $71 \%$ de organizações que assumiram ser extremamente determinante, $29 \%$ muito determinante;

5. Domínio das Línguas Locais (Yao, Emakua e Nyanja), com aproximadamente $71 \%$ de organizações que considera esta competência extremamente determinante, $15 \%$ moderadamente determinante e $14 \%$ pouco determinante;

6. Domínio da Língua Inglesa, com $15 \%$ que consideram esse aspecto extremamente determinante, $71 \%$ muito determinante e $14 \%$ pouco determinante.

64 Ha necessidade de referenciar que as competências exigidas pelos empregadores variam de acordo com a região, natureza das atividades, níveis de modernização e organização institucional. Por essa razão, uma pesquisa desenvolvida pelo Instituto de Estudos para o Emprego do Reino Unido coletou a opinião de mais de 1000 empregadores que forneceram suas percepções sobre as habilidades chaves a nível de satisfação com as habilidades dos empregados. Os resultados levaram à identificação de seis características, a saber: trabalho em equipe, interesse por aprendizagem contínua, desempenho, comunicação, aplicações numéricas, uso de tecnologias de informação e solução de problemas. Por conseguinte, a crítica principal dos empregadores é quanto à educação e o treinamento de habilidades pessoais, sociais e de comunicação, acrescentando-se ainda as falhas da formação básica na linguagem e raciocínio aritmético, nesse sentido, a maior parte dos jovens candidatos ao mercado de trabalho possui pouco dos requisitos esperados para o profissional do futuro (Campos, 2006).

$\mathrm{Na}$ acepção das organizações inquiridas, as vagas criadas pela organização nos últimos dez (10) anos até 2020, eram para as seguintes áreas profissionais: Comunicação para Mudança Social de Comportamento (CMSC); Monitoria, Estudos, Pesquisa e Advocacia Ambiental (MEPAA); Educação Cívica Ambiental (ECA); Docentes; Técnicos Profissionais; Técnicos e Auxiliares; Auxiliares Administrativos, motoristas, agentes de serviço, secretária de Direção; Assistente de Produção; Contabilista; Oficial de Marketing e Venda; Técnicos Superiores de Administração Pública e Juristas. Nestes moldes, 71,4\% nos últimos 10 anos lançou mais de 20 vagas e $28,6 \%$ dos empregadores criaram menos de 10 vagas.

O MITESS (2020b), considera que no I trimestre de 2020, na província de Niassa, foram criadas 295 vagas de emprego. Em função dos ramos de atividade, a administração pública e defesa tiveram a representação de 19,3\%; a segurança social obrigatória e atividades administrativas representam $12,4 \%$, os serviços de apoio destacam-se com cerca de $18,3 \%$, respectivamente. As áreas de saúde humana, ação social e educação com cerca de $9,4 \%$.

Espaço e Economia, 19 | 2020 
67 Em termos da avaliação que os empregadores fazem do mercado de trabalho e empregabilidade dos candidatos, numa escala de 0 a $5^{4}$, onde 0 significa muito insatisfeito e 5 Muito satisfeito. Os resultados demostram que os empregadores não estão satisfeitos com o funcionamento do mercado de trabalho da Cidade de Lichinga, no contexto da pobreza urbana nos últimos anos, visto que, $28,6 \%$ escolheu a pontuação 2 (insatisfeito) e 71,4\% atribuíram 3 pontos (mais ou menos satisfeito).

No que concerne as razões da insatisfação com o actual mercado de trabalho, apontadas pelas organizações inquiridas, são: (i) Há muito oportunismo; (ii) As vagas para emprego são lançadas quando já existem "donos" a trabalharem; (iii) Os que estão interessados, de verdade para trabalhar (com capacidades e habilidades) não são queridos, recrutam maior parte, aqueles que vão trabalhar pelo 'Dinheiro' e não como 'Servidor Público'; (iv) Muita ausência e absenteísmo ${ }^{5}$, mas com livros de ponto preenchidos, o país a perder, mas pessoas com bolsos cheios de dinheiro; e (v) os funcionários não são assíduos, estão sempre atrasados.

Essas organizações usam diversos canais para comunicar as vagas criadas, com destaque para Jornais $(28,7 \%)$, Base de dados de paralegais $(42,9 \%)$, internet/página oficial da organização (14,3\%) e vitrina (14,3\%).

\section{A procura e oferta de cursos nas instituições de ensino superior e profissional de Lichinga}

70 Os argumentos de Bourdieu e Champagnee (2008), revelam que a pobreza pode contribuir numa escolha errada do curso que o indivíduo vai frequentar numa escola, visto que, a diversificação oficial (em ramificações) ou oficiosa (em estabelecimentos ou classes escolares sutilmente hierarquizados), contribui para recriar um princípio especialmente dissimulado de diferenciação: os alunos oriundos de boas famílias receberam da família o senso do investimento, assim como os exemplos e os conselhos capazes de sustentá-lo em caso de incerteza, e estão assim em condição de investir na hora certa e no lugar certo, neste caso nas ramificações apropriadas, nas escolas certas, etc.; enquanto os oriundos de famílias pobres, na maioria dos casos abandonados a si mesmos já desde o primário, e obrigados a entregar suas escolhas à instituição escolar, ou ao acaso, para encontrar seu caminho, num universo cada vez mais complexo, e por isso votados a errar a hora e o lugar no investimento do seu reduzido capital cultural.

71 Nessa lógica, não deve ser negligenciado o facto de que a forma como a correspondência ou incompatibilidade dos cursos é interpretada, depende da função que os ensinos superiores e profissionais devem ter em relação ao mundo do trabalho. Os sistemas de ensino são organizados de maneiras diferentes e, em alguns países, diferentes níveis educacionais têm objectivos diferentes. Há aqueles que se concentram em uma preparação profissional mais direta, enquanto o ensino superior se destina a fornecer habilidades genéricas. Dentro de sistemas diferentes, os resultados esperados também variam de acordo com os diferentes programas educacionais e práticas profissionais (Nilsson, 2010). Por exemplo, o Delegado do Instituto Politécnico de Tecnologia e Empreendedorismo-IPET, em Lichinga, Paulo Amisse, destaca que há necessidade de se desenhar um estudo de base para saber as prioridades de desenvolvimento da província, de modo a orientar os cursos/programas de ensino para o contexto local. 
72 Para Nilsson (2017), a relação entre ensino superior e mercado de trabalho pode ser estudada sob várias perspectivas. Nessa lógica, a correspondência entre educação e mercado de trabalho pode ser descrita em termos de diferentes tipos de desequilíbrios estruturais entre oferta e demanda relacionados ao número de estudantes formados em diferentes programas de ensino superior e políticas do mercado de trabalho. Por exemplo, em 2016, a Província do Niassa contou com 1.472 escolas (entre públicas, comunitárias e privadas), tendo registrados um crescimento de 3,9\% em relação a 2015. Ainda, a província conta com 5 instituições do ensino superior. A taxa de analfabetismo situou-se em $58,0 \%$, sendo $42,6 \%$ nos homens e $72 \%$ nas mulheres, posicionando-se na segunda maior da região Norte (Governo do Niassa, 2017). o que demostra que há necessidade de se investir mais na educação. Através da análise das entrevistas destinadas aos dirigentes, formadores e docentes das Instituições de Ensino Superior e Ensino Profissional, com representações em Lichinga, foi possível mapear os cursos oferecidos, a duração dos mesmos e sua aceitação no mercado (procura).

Observa-se que os cursos que muitas IES oferecem e com mais mercado e empregabilidade em Lichinga são: Direito, Administração Pública e Contabilidade que estão relacionadas as áreas de ciências sociais, negócios e direito. No entanto, existem outras áreas que são lecionadas por poucas faculdades especializadas que tem tido muita procura por parte dos candidatos, como passamos a citar: Engenharia de Desenvolvimento Rural, Engenharia Florestal, Gestão Ambiental, Gestão de Recursos Humanos, Agropecuária, Psicologia, Gestão de Recursos Florestais \& Faunísticos e Mestrado em Gestão e Administração Educacional (Anexo I).

Portanto, há necessidade de fazer referência que o ingresso no ensino superior em Lichinga não tem sido tarefa fácil, pois, os candidatos aos cursos oferecidos nas IES públicas que são mais baratas são filtrados por meio de exames de admissão, excluindo muitos desta corrida, em contrapartida a opção das IES privadas exige uma capacidade financeira para custear as mensalidades/propinas e outras coimas escolares. No caso de Instituições de Educação Profissional entrevistadas, os cursos que tem maior aderência de candidatos são os oferecidos pelos institutos públicos, nomeadamente, Enfermagem Saúde Materna Infantil, Corte \& Costura, Eletricidade, Canalização, Administração Pública, Contabilidade, Eletricidade Industrial, Construção Civil, Mecânica Auto, Extensão Agrária, Agricultura Geral e Pecuária (Anexo II).

Neste raciocínio de ideias, na perspectiva de Amide (2014), dos alunos que terminam a $12^{a}$ classe, e não realizam as suas expectativas de continuar a estudar no Ensino Superior, são muitos que não são absorvidos nos cursos técnico-profissionais que, por sua vez, são poucos, tais como dois Institutos de Formação de Professores, um em Cuamba e outro em Lichinga; um Instituto Agrário em Lichinga; um Instituto de Ecoturismo em Marrupa; o IFAPA em Lichinga. O pior ainda, alguns alunos com $12^{\mathrm{a}}$ Classe já concluída, preferem se ingressar em cursos profissionais básicos para garantirem alguma profissão no seu futuro; outros preferem se ingressar nas fileiras da polícia, outros ainda são "voluntários" para o Serviço Militar; e muitos ainda continuam a alimentar a expectativa de estudar no Ensino Superior mas permanecendo na situação de não estar a fazer nada ou então a praticar pequenos negócios de compra e venda de amendoim, refrigerantes, e outros produtos agrícolas ou pecuária.

76 Entendemos assim, que a educação em Lichinga funciona como uma válvula de escape para evitar a marginalização de jovens (pratica de criminalidade, prostituição, gravidez indesejadas, casamentos prematuros) e cria uma esperança ilusória de que um dia irão 
conseguir um emprego e "mudar de vida". Logo, a educação profissional e superior são ferramentas de mobilidade e exclusão social nesta cidade. Os resultados encontrados na pesquisa desenvolvida por Angst (2014), nos remetem também a ideia de que em Lichinga o ingresso no Ensino Superior tem sido valorizado como principal caminho a ser trilhado pelos jovens que chegam ao fim do Ensino Secundário. Os dados informam que mesmo não conseguindo ingressar no Ensino Superior imediatamente após concluir o ensino secundário por motivos financeiros a educação superior é a expectativa consolidada entre os jovens.

Os cursos apresentados e analisados neste capítulo, que atualmente são oferecidos pela Universidade Católica de Moçambique-UCM, Universidade Rovuma-UniROVUMA, Universidade Lúrio-UniLURIO, ISGECOF, Centro de Formação de Saúde de Lichinga, Instituto de Formação Profissional e Estudos Laborais Alberto Cassimo-IFPELAC, Instituto Politécnico de Tecnologia e Empreendedorismo-IPET, Instituto Industrial e Comercial Ngungunhana, Instituto Agrário de Lichinga, adequam-se aos desafios da cidade e província de Niassa, contudo, um estudo de viabilidade, conforme foi sugerido por Paulo Amisse, pode ser uma solução racionalmente segura para repensar em cursos novos que se ajustam aos desafios de desenvolvimento econômico local.

\section{Considerações Finais}

O nível de empregabilidade dos candidatos a emprego na cidade de Lichinga ainda é alto, pois, os quadros qualificados são empregáveis, apesar da existência duma dicotomia entre o número de pessoas formadas e a disponibilidade de vagas no mercado de trabalho local. Isso significa que, os candidatos formados nesta cidade tem limitações para o ingresso no mercado de trabalho devido ao número reduzido de organizações públicas, privadas e do terceiro sector (ONG's) a operarem localmente. No entanto, alguns cursos oferecidos pelas Instituições do Ensino Superior (IES) e de Educação Profissional (IEP) em Lichinga adequam-se mais ao mercado e são muito solicitados, nomeadamente, Licenciaturas em Direito, Agropecuária, Gestão Ambiental, Gestão de Recursos Humanos, Contabilidade, Gestão de Recursos Florestais \& Faunísticos, Mestrado em Gestão e Administração Educacional; cursos médios em Enfermagem Saúde Materna Infantil, Administração Pública, Contabilidade, Eletricidade Industrial, Construção Civil, Mecânica Auto, Extensão Agrária, Agricultura Geral, Pecuária; e os cursos de curta duração de Corte e Costura, Eletricidade e Canalização.

79 Estrategicamente, pensa-se que há necessidade de investir em cursos associados às engenharias, tecnologias, medicina e ciências exatas, como uma solução de longo prazo para explorar os recursos naturais de forma sustentável e promover um desenvolvimento endógeno. Mas, em Lichinga, há falta de empresas que funcionam como agências de emprego e pouca orientação profissional dos graduados das universidades para enfrentarem o mercado de trabalho. Isso constitui um entrave para que os candidatos sejam competitivos, na medida em que, os jovens saem da academia sem nenhuma informação adequada sobre os desafios reais, tabelas salariais e oportunidades disponíveis. Esse facto é agravado com o elevado índice de venda de vagas de emprego que foi apontado por mais de $65 \%$ dos inquiridos como sendo uma prática comum, constituindo assim a principal lacuna da empregabilidade, pois, 
desacredita as instituições e cria uma concorrência desleal, onde a ideia de mérito é substituída pelo nepotismo e corrupção.

No entanto, reparando para a representatividade das respostas, verificou-se que as instituições com mais casos de corrupção nos concursos de ingresso são as que pertencem ao aparelho do Estado, visto que, são o maior número de organizações existentes na cidade de Lichinga. Quanto a influência das competências exigidas pelos empregadores no funcionamento do mercado de trabalho local, observou-se que os empregadores exigem mais experiência, qualificação e especialização, em contrapartida a maior parte dos candidatos de emprego não reúnem nenhuma experiência, o que denota um modus vivendi característico entre os estudantes da região, visto que, muitos esperam terminar a educação formal para depois ir atrás do primeiro emprego, ao invés de acumular a experiência durante o período em que frequentam à escola.

Nessa perspectiva, esta pesquisa chegou a conclusão de que a fraca absorção de recursos humanos qualificados no mercado de trabalho da cidade de Lichinga, promove a fuga do capital humano para outros centros urbanos, por conseguinte, os que permanecem acabam sendo marginalizados, desempenhando funções fora da sua área de especialização e aceitam oportunidades com péssimas condições de trabalho. Logo, o mau ambiente de negócios nesta cidade e a corrupção, retira a possibilidade dos recémgraduados apostarem no empreendedorismo e no auto-emprego. Esses fatores, vistos de forma conjugada, acabam perpetuando o ciclo da pobreza urbana nas famílias que viam a educação como uma salvação para alcançar o bem-estar e mobilidade social, mas também, distorce o funcionamento do mercado de trabalho local.

ANEXOS

Anexo I. Cursos ministrados nas IES em Lichinga e seu mercado (2019/2020)

\begin{tabular}{|c|c|c|c|}
\hline NOME DA IES & NOME DO CURSO OU PROGRAMA & Duração & $\begin{array}{l}\text { Observações e Notas sobre o } \\
\text { mercado dos cursos }\end{array}$ \\
\hline \multirow{7}{*}{ UCM } & $\begin{array}{l}\text { Licenciatura em Gestão de Recursos } \\
\text { Florestais e Faunísticos }\end{array}$ & 4 anos & Tem muita procura \\
\hline & $\begin{array}{l}\text { Licenciatura em Contabilidade e } \\
\text { Auditoria }\end{array}$ & 4 anos & Tem procura mediana \\
\hline & Licenciatura em Direito & 4 anos & Tem procura mediana \\
\hline & Mestrado em Administração Pública & $\begin{array}{l}1 \text { ano e } \\
\text { meio }\end{array}$ & Tem procura mediana \\
\hline & Mestrado em Direito Administrativo & $\begin{array}{l}1 \text { ano e } \\
\text { meio }\end{array}$ & Tem procura mediana \\
\hline & $\begin{array}{l}\text { Mestrado em Gestão e Administração } \\
\text { Educacional }\end{array}$ & $\begin{array}{l}1 \text { ano e } \\
\text { meio }\end{array}$ & Tem mais procura \\
\hline & $\begin{array}{l}\text { Mestrado em Gestão e Administração } \\
\text { de Negócios (MBA) }\end{array}$ & $\begin{array}{l}1 \text { ano e } \\
\text { meio }\end{array}$ & Tem procura mediana \\
\hline UniROVUMA/ & Licenciatura em Geografia & 4 anos & Tem procura mediana \\
\hline
\end{tabular}




\begin{tabular}{|c|c|c|c|}
\hline & Licenciatura em História & 4 anos & Tem uma procura mediana \\
\hline & Licenciatura em Psicologia & 4 anos & Tem muita procura \\
\hline & Licenciatura em Biologia & 4 anos & Tem procura mediana \\
\hline & Licenciatura em Português & 4 anos & Te procura mediana \\
\hline & Licenciatura em Agro-pecuária & 4 anos & Tem muita procura \\
\hline & Licenciatura em Contabilidade & 4 anos & Tem muita procura \\
\hline & Licenciatura em Inglês & 4 anos & Tem procura mediana \\
\hline & Licenciatura em Direito & 4 anos & Tem muita procura \\
\hline & $\begin{array}{l}\text { Licenciatura em Gestão de Recursos } \\
\text { Humanos }\end{array}$ & 4 anos & Tem muita procura \\
\hline UniLurio & $\begin{array}{l}\text { Licenciatura em Engenharia de } \\
\text { Desenvolvimento Rural }\end{array}$ & 4 anos & Tem muita procura \\
\hline & Licenciatura em Engenharia Florestal & 4 anos & Tem muita procura \\
\hline & $\begin{array}{l}\text { Licenciatura em Contabilidade e } \\
\text { Auditoria }\end{array}$ & 4 anos & Tem procura mediana \\
\hline & $\begin{array}{l}\text { Licenciatura em Administração } \\
\text { Pública e Autárquica }\end{array}$ & 4 anos & Tem procura mediana \\
\hline & $\begin{array}{l}\text { Licenciatura em Administração } \\
\text { Pública, Comercio e Finanças }\end{array}$ & 4 anos & Tem pouca procura \\
\hline & Licenciatura em Gestão Ambiental & 4 anos & Tem muita procura \\
\hline & Licenciatura em Economia & 4 anos & Tem pouca procura \\
\hline & Licenciatura em Direito & 4 anos & Tem muita procura \\
\hline & $\begin{array}{l}\text { Licenciatura em Gestão de Recursos } \\
\text { Humanos }\end{array}$ & 4 anos & Tem muita procura \\
\hline
\end{tabular}

Anexo II. Cursos ministrados nas IEP em Lichinga até 2019/20

\begin{tabular}{|l|l|l|l|}
\hline NOME DA IEP & NOME DO CURSO OU PROGRAMA & Duração & $\begin{array}{l}\text { Observações e Notas sobre } \\
\text { o mercado dos cursos }\end{array}$ \\
\hline $\begin{array}{l}\text { Centro de Formação de } \\
\text { Saúde de Lichinga }\end{array}$ & $\begin{array}{l}\text { ESMI-Enfermagem Saúde } \\
\text { Materna Infantil }\end{array}$ & 2 anos & Tem muita procura \\
\hline
\end{tabular}




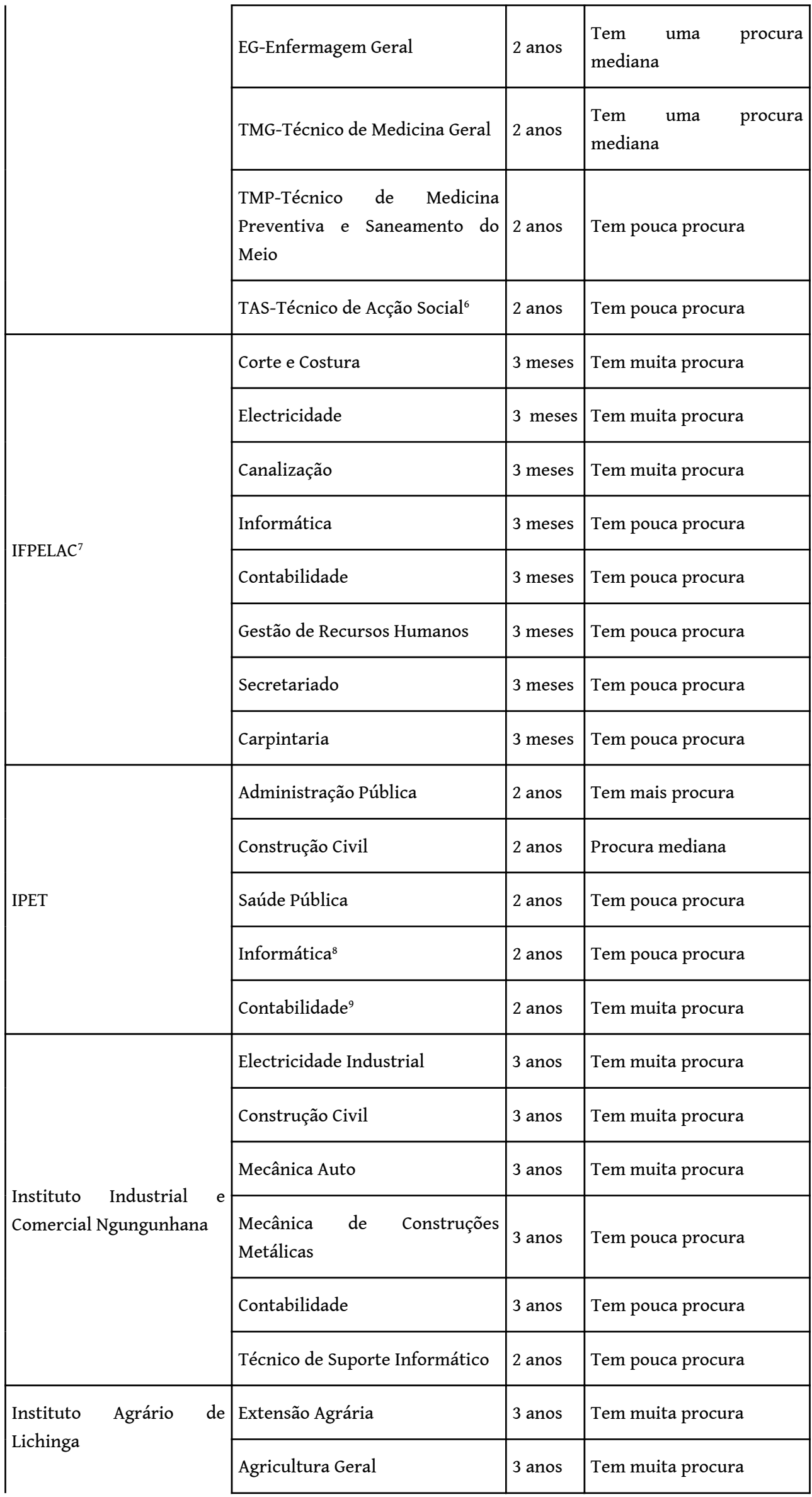




\begin{tabular}{|l|l|l|}
\hline Pecuária & 3 anos & Tem muita procura \\
\hline Mecanização & 3 anos & Procura mediana \\
\hline
\end{tabular}

Anexo III. Lista de Entrevistados

\begin{tabular}{|c|c|c|c|}
\hline Nome & Função & Data & Hora \\
\hline Jorge Nassera & Formador do Centro de Formação de Saúde de Lichinga & $\begin{array}{l}27 \text { de Maio } \\
\text { de } 2020\end{array}$ & $12: 50^{\prime}$ \\
\hline Paulo Matapa & Delegado Provincial do IFPELAC-Niassa & $\begin{array}{l}27 \text { de Maio } \\
\text { de } 2020\end{array}$ & $13: 30^{\prime}$ \\
\hline Paulo Amisse & Delegado Provincial do IPET-Niassa & $\begin{array}{l}27 \text { de Maio } \\
\text { de } 2020\end{array}$ & $16: 30^{\prime}$ \\
\hline $\begin{array}{l}\text { Felipe André } \\
\text { Angst, } \mathrm{PhD}\end{array}$ & $\begin{array}{l}\text { Director da Faculdade de Gestão de Recursos Florestais e } \\
\text { Faunísticos (FAGREFF) da Universidade Católica de } \\
\text { Moçambique-Niassa }\end{array}$ & $\begin{array}{l}28 \text { de Maio } \\
\text { de } 2020\end{array}$ & 07:11' \\
\hline $\begin{array}{l}\text { Agostinho } \\
\text { Molesse }\end{array}$ & $\begin{array}{l}\text { Docente Universitário e participou na Comissão instaladora } \\
\text { da UP (UniRovuma)-Niassa }\end{array}$ & $\begin{array}{l}29 \text { de Maio } \\
\text { de } 2020\end{array}$ & $10: 20$ \\
\hline Almeida Paulo & $\begin{array}{l}\text { Formador do Instituto Industrial e Comercial Ngungunhana- } \\
\text { Lichinga }\end{array}$ & $\begin{array}{l}26 \text { de Maio } \\
\text { de } 2020\end{array}$ & $09: 47^{\prime}$ \\
\hline $\begin{array}{l}\text { Valente } \\
\text { Nhampalela }\end{array}$ & Assessor do Reitor e docente universitário do ISGECOF & $\begin{array}{l}29 \text { de Maio } \\
\text { de } 2020\end{array}$ & $10: 00$ \\
\hline $\begin{array}{l}\text { Luís } \quad \text { Manuel } \\
\text { Cuinica }\end{array}$ & Director do Instituto Agrário de Lichinga & $\begin{array}{l}3 \text { de Junho } \\
\text { de } 2020\end{array}$ & $14: 00^{\prime}$ \\
\hline $\begin{array}{ll}\text { Leonid } & \text { Carlos } \\
\text { Moisés } & \end{array}$ & $\begin{array}{l}\text { Director da Faculdade de Ciências Agraria da UniLúrio } \\
\text { (Universidade Lúrio) em Niassa }\end{array}$ & $\begin{array}{l}6 \text { de Junho } \\
\text { de } 2020\end{array}$ & $12: 00^{\prime}$ \\
\hline
\end{tabular}

Lista de Abreviaturas

BAD: Banco Africano de Desenvolvimento

DEEF: Direção de Estudos Econômicos e Financeiros

DNEAP: Direção Nacional de Estudos e Análise de Políticas

EG: Enfermagem Geral

ESMI: Enfermagem Saúde Materna Infantil

IAF: Inquérito aos Agregados Familiares

IFPELAC: Instituto de Formação Profissional e Estudos Laborais Alberto Cassimo

INE: Instituto Nacional de Estatística

IOF: Inquérito aos Agregados Familiares sobre Orçamento Familiar 
IPET: Instituto Politécnico de Tecnologia e Empreendedorismo

ISGECOF: Instituto Superior de Gestão, Comercio e Finanças

MBA: Mestrado em Gestão e Administração de Negócios

MEF: Ministério da Economia e Finanças

MPD: Ministério de Planificação e Desenvolvimento

OECD: Organização para Cooperação Econômica e Desenvolvimento

ONG’s: Organizações Não-governamentais

ONU: Organização das Nações Unidas

OSC: Organizações da Sociedade Civil

PEN: Plano Estratégico do Niassa

PNUD: Programa das Nações Unidas para o Desenvolvimento

TAS: Técnico de Ação Social

TMG: Técnico de Medicina Geral

TMP: Técnico de Medicina Preventiva e Saneamento do Meio

UCM: Universidade Católica de Moçambique

UniLURIO: Universidade Lúrio

UniROVUMA: Universidade Rovuma

UP: Universidade Pedagógica

\section{BIBLIOGRAFIA}

ALI, R.. Dinâmicas e dilemas do emprego, trabalho e bem-estar nas agroindústrias florestais em Niassa. In: CASTEL-BRANCO, C. et al (ed.). Emprego e transformação econômica e social em Moçambique. Maputo: IESE, 2017. p. 209-254.

ALMEIDA, M. L. P. P.. Diplomados e mercado de trabalho: estudo de uma instituição do ensino superior politécnico. Tese (Doutoramento em Ciências da Educação), Universidade do Porto, 2014.

AMIDE, J. B.. Absorção de alunos do Ensino Secundário pelo Ensino Superior na Província do Niassa (2011-2013). In: Simone Mura (Ed.). Transições: entre o ensino secundário, o ensino superior e o mercado de trabalho. Beira: Universidade Católica de Moçambique, 2014. p. 102-117.

ANGST, F. A.. Expectativas dos finalistas das Escolas do Ensino Secundário da Cidade de Lichinga. In: Simone Mura (Ed.). Transições: entre o ensino secundário, o ensino superior e o mercado de trabalho. Beira: Universidade Católica de Moçambique, 2014. p. 162-169.

BAD, OECD E PNUD (2017). African Economic Outlook 2017: ENTREPRENEURSHIP AND INDUSTRIALISATION. Disponivel em: https://www.afdb.org/fileadmin/uploads/afdb/Documents/ Publications/AEO_2017_Report_Full_English.pdf. acessado aos 15 de Maio de 2020. 
BANCO AFRICANO DE DESENVOLVIMENTO (BAD) (2013). Recognizing Africa's Informal Sector. Disponivel em: http://www.afdb.org/en/blogs/afdb-championing-inclusive-growth-across africa/post/recognizingafricas-informal-sector-11645/, acessado aos 15 de Maio de 2020.

BANCO MUNDIAL. Doing Business Moçambique 2019.Maputo: International Bank for Reconstruction and Development /The World Bank, 2019, 167p.

BANCO MUNDIAL. Grande Maputo: pobreza urbana e crescimento inclusivo. Maputo: The World Bank, 2017, 41p.

BARBEDO, J. M. R.. Textura da Pobreza Urbana: Métodos de análise espacial de apoio à formulação de políticas urbanas de redução da pobreza em Regiões Metropolitanas da África Sub-Sahariana - o caso de estudo de Luanda. Dissertação (Mestrado em Planeamento e Projecto do Ambiente Urbano)- Curso de Planeamento do Território e Ambiente, Universidade do Porto, 2007.

BARBOSA, M. P., Petterini, F. C., Ferreira, R. T.. Composição do capital humano, crescimento económico e produtividade total dos factores nos municípios brasileiros. p. 1-22, 2011.

BATONE, D. C.. Os Desafios da Expansão do Ensino Superior e a Formação do Capital Humano em Moçambique. Researchgate, Maputo, p. 1-27, 2020.

BECKER, G. S.. Human Capital: a theoretical and empirical analysis, with special reference to education. 3 ed. Chicago: University of Chicago Press,1993. 390 p.

BECKER, G.S.. Human Capital: A Theoretical Analysis with Special Reference to Education. New York: Columbia University Press, 1962.220 p.

BOLLES, R. N. Como conseguir um emprego e descobrir a sua profissão ideal: qual a cor de seu páraquedas?. 2 ed. Rio de Janeiro: Sextante, 2000. 280 p.

BORJAS, G. J.. Economic theory and international migration. International Migration Review. v. 23, n. 3, Special Silver Anniversary Issue: International Migration an Assessment for the 90's, 1989. p. 457-485.

BOURDIEU, P., CHAMPAGNE, P.. Os excluídos do interior. 7ed. In: BOURDIEU, P. et al. A Miséria do Mundo. Petrópolis, RJ: Vozes, 2008. p. 481-486.

BRESSER-PEREIRA, L. C.. A organização e o novo conceito de capital no capitalismo dos profissionais. Textos para Discussão, 2011. p. 1-17.

CAMPOS, K. C. L.. Construção de uma Escala de Empregabilidade: competências e habilidades pessoais, escolares e organizacionais. Tese (Doutoramento em Psicologia)-Curso de Psicologia Escolar e do Desenvolvimento Humano, Universidade de São Paulo, 2006.

COLLIER, P.. Os Milhões da Pobreza: Por que motivo os países mais carenciados do mundo estão a ficar cada vez mais pobres? Qual a verdadeira chave para o seu crescimento?. Lisboa: Casa das Letras, 2007, $261 \mathrm{p}$.

CTA. Impacto do COVID-19 no Sector Empresarial Moçambicano e Propostas de Medidas para a sua Mitigação. Maputo, Confederação Das Associações Económicas De Moçambique, 2020.

ENGELS, F. A Situação da Classe Trabalhadora na Inglaterra. São Paulo: Boitempo, 2010, 385 p. GOVERNO DO NIASSA. Plano Estratégico do Niassa (2018-2024). Lichinga, 2017, 77 p.

INE. Estatísticas do Distrito: Cidade de Lichinga. Maputo, Instituto Nacional de Estatística, 2017, 29 p.

INE. Indicadores econômico-financeiros das empresas 2016. Maputo, Instituto Nacional de Estatistica, 2018, 104 p. 
Intervenção de Sua Excelência Filipe Jacinto Nyusi, Presidente da República de Moçambique, por Ocasião da Inauguração da Direção Provincial do Trabalho, Emprego e Segurança Social de Niassa. Maputo, 30 de Março de 2016. Disponível em: http://www.mitess.gov.mz/sites/default/files/press-release/ files/Disc\%20Inaug\%20Dir\%20Prov\%20Trabalho\%20\%20Lichinga\%20\%281\%29.pdf. Acessado aos 20 de Maio de 2020.

Jornal Mwatengue, Lichinga, 05 de Jun. 2020, p. 3.

KELNIAR, V. C., LOPES, J. L., PONTILI, R. M. A teoria do capital humano: revisitando conceitos. 2013.

KNIGHT, P.T., YORKE, M.. Learning, Curriculum and Employability in Higher Education. London: Routledge, 2004, 185 p.

MALOA, J. M.. A Urbanização Moçambicana: uma proposta de interpretação. Tese (doutoramento em Ciências)- Programa de Pós-graduação, Universidade de São Paulo, 2016.

MALSCHITZKY, N.. Empregabilidade: um modelo para a instituição de ensino superior orientar e encaminhar a carreira profissional dos acadêmicos. Tese (Doutoramento em Engenharia de Produção)- Programa de Pós-Graduação em Engenharia de Produção, Universidade Federal de Santa Catarina, 2004.

MARX, K.. O Capital: crítica da economia política. São Paulo: Editora Nova Cultural Ltda, 1996, 483 p. MEF/DEEF. pobreza e bem-estar em moçambique: quarta avaliação nacional (IOF 2014/15). Maputo: Ministério de Economia e Finanças/Direcção de Estudos Econômicos e Financeiros, 2016, 112 p. MITESS. Boletim de Estatísticas do Trabalho - 2018. Maputo: Ministério do Trabalho, Emprego e Segurança Social, 2019, 44 p.

MITESS. Boletim de Estatísticas do Trabalho-2019. Maputo: Ministério do Trabalho e Segurança Social, 2020b, $44 \mathrm{p}$.

MITESS. Boletim Informativo do Mercado do Trabalho - I Trimestre 2020. Maputo: Ministério do Trabalho e Segurança Social, 2020a, 36 p.

MPD/DNEP.. Pobreza e bem-estar em Moçambique: terceira avaliação nacional. Maputo: Ministério da Planificação e Desenvolvimento/Direção Nacional de Estudos e Análise de Políticas, 2010, 140 p.

NILSSON, S., EKBERG, K.. Employability and work ability: Returning to the labour market after long-term absence. Work, v. 4, 2014, p. 449-457.

NILSSON, S.. Employability, employment and the establishment of higher education graduates in the labour market. In M. Tomlinson \& L. Holmes (ed.). Graduate Employability in Context: Theory, research and debate. London: Palgrave Macmillan, 2017. p. 65-85.

NILSSON, S.. On the meaning of higher education in professional practice: the case of physicians and engineers. Journal of Education and Work. v. 3, p. 255-74, 2010.

PEDROSO, P., FERREIRA, A. C., DORNELAS, A., ESTANQUE, E., CENTENO, M., NOVO, A., HENRIQUES, M.. Acesso ao emprego e mercado de trabalho: formulação de políticas públicas no horizonte de 2013. Coimbra, Universidade de Coimbra, 2005, 196p.

RODRIGUES, E. V., SAMAGAIO, F., FERREIRA, H., MENDES, M. M., JANUÁRIO, S.. A Pobreza e a Exclusao Social: Teorias, Conceitos e Politicas Sociais em Portugal. p. 63-101, 2000.

SANTOS, M. A., BARBIERI, A. F., CARVALHO, J. A. M., MACHADO, C. J. Migração: uma revisão sobre algumas das principais teorias. UFMG/Cedeplar, p. 6-17, 2010.

SCHUMPETER, J. A.. Capitalismo, Socialismo e Democracia. Rio de Janeiro: Editora Fundo de Cultura, 1961. $487 \mathrm{p}$. 
SCHUMPETER, J. A.. Teoria do desenvolvimento econômico: uma investigação sobre lucros, capital, crédito, juro e o ciclo econômico. São Paulo: Editora Nova Cultural Ltda, 1997. 237 p.

SEN, A. K.. Desenvolvimento como liberdade. 1 ed. São Paulo: Companhia das Letras, 2000. 416 p. SMITH, V.. Review article: Enhancing employability - Human, cultural, and social capital in an era of turbulent unpredictability. Human Relations, v. 2, p. 279-300, 2010.

SOUZA, M. A. A.. Abordagens Recentes da Pobreza Urbana. Mercator. Fortaleza, v. 17, p. 1-19, 2018.

STIGLITZ, J. E.. Políticas de Desenvolvimento no Mundo Globalizado. Desenvolvimento e Globalização, p. 333-356, 2003.

UCAMA, A. C. D.. Os Desafios Legais para a Inserção dos Recém-Graduados no Mercado de Trabalho - o Contrato de Aprendizagem. In: Simone Mura (Ed.). Transições: entre o ensino secundário, o ensino superior e o mercado de trabalho. Beira: Universidade Católica de Moçambique, 2014. p. 87-100.

UNU MULHERES. (2015). Facts and Figures: Economic Empowerment. Disponivel em: http:// www.unwomen.org/en/what-we-do/economic-empowerment/facts-and-figures. acessado aos 15 de Maio de 2020.

VASCONCELOS, P. A.. pobreza urbana e a formação de bairros populares em Salvador na longa duração. GEOUSP - Espaço e Tempo. São Paulo, n. 20, p. 19-30, 2006.

Fonte: Dados da pesquisa preparados através dos planos curriculares e entrevistas aos docentes e dirigentes das IES.

Fonte: Dados da pesquisa preparados através dos planos curriculares e entrevistas aos formadores e dirigentes das IEP.

\section{NOTAS}

1. Conferir o "O CAPITAL-CRÍTICA DA ECONOMIA POLÍTICA”, p.41.

2. Conferir o discurso completo no site: http://www.mitess.gov.mz/sites/default/files/pressrelease/files/Disc\%20Inaug\%20Dir\%20Prov\%20Trabalho\%20\%20Lichinga\%20\%281\%29.pdf. Acessado aos 20 de Maio de 2020, pelas 22 horas.

3. A pontuação é normalizada e vai de 0 a 100 com 100 a representar o melhor desempenho regulatório (quanto mais alta for a pontuação, melhor).

4. Quanto maior a pontuação evidencia um maior grau de satisfação positiva com o mercado de trabalho.

5. Trata-se de faltas/ausências recorrentes do funcionário, no local de trabalho, alegando motivos diversos.

6. O curso existe, mas não esta a correr por falta de inscritos.

7. Tem parcerias com a UniRovuma (ex-UP-Universidade Pedagógica) e UniLurio para ministrar os cursos com a melhor qualidade. E no fim dos cursos os formados organizam-se em grupos de 3 a 5 pessoas para formarem pequenas cooperativas ou associações para beneficiarem de quits $\mathrm{e}$ iniciarem um negócio na área, como também empregar outros jovens da Cidade de Lichinga.

8. Foi descontinuado em 2020 e sera reintroduzido em 2021.

9. Foi descontinuado em 2020 e sera reintroduzido em 2021.

10. Foi descontinuado em 2019 por falta de docentes especializados. 


\section{RESUMOS}

Propusemo-nos a analisar a empregabilidade e mercado de trabalho na Cidade de Lichinga, num contexto em que as últimas avaliações sobre a pobreza demonstram que a província de Niassa experimentou nos últimos anos um aumento da pobreza, de 31.9\% em 2008/09 para $65.3 \%$ em 2014/15. Com o recurso a pesquisa bibliográfica, entrevistas, inquéritos e estatísticas oficiais foi possível chegar a resultados válidos. As sensibilidades dos candidatos a emprego inquiridos evidenciam que a admissão para o mercado de emprego não tem sido baseado em critérios meritórios, mas sim por práticas clientelistas e corruptas associadas a compra das vagas criadas, com destaque para as organizações públicas, fragilizando assim o mercado de trabalho, descredibilizando as instituições e criando uma concorrência desleal. 0 estudo conclui que a fraca absorção de quadros formados pelo mercado de trabalho local promove a fuga do capital humano para outros centros urbanos, mas também a marginalização dos quadros que permanecem na cidade desempenhando funções fora da sua área de especialização com péssimas condições de trabalho e o mau ambiente de negócios retrai o auto-emprego. Esses fatores associados perpetuam o ciclo da pobreza urbana das famílias que viam a educação como uma salvação para alcançar o bem-estar e mobilidade social em Lichinga.

We set out to analyze the employability and labour market in Lichinga, in a context where the latest poverty assessments show that Niassa province has experienced poverty increases in recent years, from $31.9 \%$ in $2008 / 09$ to $65.3 \%$ in $2014 / 15$. Using bibliographic research, interviews, surveys, and official statistics, it was possible to reach valid results. The sensitivities of the jobseekers surveyed show that admission to the job market has not been based on meritorious criteria, but rather by patronage and corrupt practices associated with the purchase of vacancies created, especially public organizations, thus weakening the labor market, discrediting institutions and creating unfair competition. The study concludes that the poor absorption of staff formed by the local labor market promotes the flight of human capital to other urban centers, but also the marginalization of the staff who remain in the city performing functions outside their area of specialization with poor working conditions and the bad business environment retracts self-employment. These associated factors perpetuate the cycle of urban poverty of families who saw education as a salvation to achieve social well-being and mobility in Lichinga.

Nos propusimos analizar la empleabilidad y el mercado laboral en la ciudad de Lichinga, en un contexto en el que las últimas evaluaciones de pobreza muestran que la provincia de Niassa ha experimentado un aumento de la pobreza en los últimos años, del 31,9\% en 2008/09 a El 65,3\% en 2014/15. Con el uso de investigaciones bibliográficas, entrevistas, encuestas y estadísticas oficiales, fue posible llegar a resultados válidos. Las sensibilidades de los solicitantes de empleo encuestados muestran que la admisión al mercado laboral no se ha basado en criterios meritorios, sino en prácticas clientelistas y corruptas asociadas con la compra de vacantes creadas, con énfasis en las organizaciones públicas, debilitando así la mercado laboral, desacreditar instituciones y crear competencia desleal. El estudio concluye que la débil absorción de personal capacitado por el mercado laboral local promueve la fuga de capital humano a otros centros urbanos, pero también, la marginación del personal que permanece en la ciudad desempeñando funciones fuera de su área de especialización con terribles condiciones de empleo. El trabajo y el mal ambiente de negocios frena el autoempleo. Estos factores asociados perpetúan el ciclo de pobreza urbana de las familias que vieron la educación como una línea vital para lograr el bienestar y la movilidad social en Lichinga. 
Nous avons entrepris d'analyser l'employabilité et le marché du travail dans la ville de Lichinga, dans un contexte dans lequel les dernières évaluations de la pauvreté montrent que la province de Niassa a connu une augmentation de la pauvreté ces dernières années, passant de $31,9 \%$ en 2008/09 à 65,3\% en 2014/15. Grâce à la recherche bibliographique, aux entretiens, aux enquêtes et aux statistiques officielles, il a été possible d'obtenir des résultats valides. Les sensibilités des demandeurs d'emploi interrogés montrent que l'admission sur le marché du travail n'a pas été basée sur des critères méritoires, mais plutôt sur des pratiques clientélistes et corrompues associées à l'achat de postes vacants créés, en mettant l'accent sur les organisations publiques, affaiblissant ainsi le marché du travail, discréditant les institutions et créant une concurrence déloyale. L'étude conclut que la faible absorption de personnel formé par le marché du travail local favorise la fuite du capital humain vers d'autres centres urbains, mais aussi, la marginalisation du personnel qui reste en ville exerçant des fonctions en dehors de son domaine de spécialisation avec des conditions d'emploi terribles. le travail et le mauvais environnement des affaires freinent le travail indépendant. Ces facteurs associés perpétuent le cycle de la pauvreté urbaine pour les familles qui considéraient l'éducation comme une bouée de sauvetage pour atteindre le bien-être et la mobilité sociale à Lichinga.

\section{ÍNDICE}

Palabras claves: empleabilidad, desempleo, mercado laboral y pobreza.

Mots-clés: employabilité, chômage, marché du travail et pauvreté.

Palavras-chave: empregabilidade, desemprego, mercado de trabalho e pobreza.

Keywords: employability, unemployment, labor market and poverty.

\section{AUTOR}

\section{DOMINGOS CARLOS BATONE}

Docente Universitário e Coordenador de Estudos e Projetos na ESEG - Escola Superior de Economia e Gestão, Maputo. Licenciado/Graduado em Administração Pública pela Universidade Eduardo Mondlane (UEM) e Mestrando em Administração Pública e Desenvolvimento na Universidade Joaquim Chissano (UJC). Tem desenvolvido estudos e consultorias para ONG's e empresas privadas.

Endereço electrónico para correspondências: dcbatone@gmail.com, domingos.batone@eseg.ac.mz. 